\title{
Protocol of the PSYCHOTSH study: association between neonatal thyroid stimulating hormone concentration and intellectual, psychomotor and psychosocial development at 4-5 year of age: a retrospective cohort study
}

\author{
Caroline Trumpff ${ }^{1} 2^{*}$, Johan Vanderfaeillie ${ }^{3}$, Nathalie Vercruysse ${ }^{2}$, Jean De Schepper ${ }^{4}$, Jean Tafforeau ${ }^{1}$, \\ Herman Van Oyen ${ }^{1}$ and Stefanie Vandevijvere ${ }^{1}$
}

\begin{abstract}
Background: Several European countries, including Belgium, still suffer from mild iodine deficiency. Thyroid stimulating hormone (TSH) concentration in whole blood measured at birth has been proposed as an indicator of maternal iodine status during the last trimester of pregnancy. It has been shown that mild iodine deficiency during pregnancy may affect the neurodevelopment of the offspring. In several studies, elevated TSH levels at birth were associated with suboptimal cognitive and psychomotor outcomes among young children. This paper describes the protocol of the PSYCHOTSH study aiming to assess the association between neonatal TSH levels and intellectual, psychomotor and psychosocial development of 4-5 year old children. The results could lead to a reassessment of the recommended cut-off levels of $5>\mathrm{mU} / \mathrm{L}$ used for monitoring iodine status of the population.

Methods: In total, 380 Belgian 4-5 year old preschool children from Brussels and Wallonia with a neonatal blood spot TSH concentration between 0 and $15 \mathrm{mU} / \mathrm{L}$ are included in the study. For each sex and TSH-interval $(0-1,1-2,2-3$, $3-4,4-5,5-6,6-7,7-8,8-9$ and 9-15 mU/L), 19 newborns were randomly selected from all newborns screened by the neonatal screening centre in Brussels in 2008-2009. Infants with congenital hypothyroidism, low birth weight and prematurity were excluded from the study. Neonatal TSH concentration was measured by the Autodelphia method in dried blood spots, collected by heel stick on filter paper 3 to 5 days after birth. Cognitive abilities and psychomotor development are assessed using the Wechsler Preschool and Primary Scale of Intelligence - third edition - and the Charlop-Atwell Scale of Motor coordination. Psychosocial development is measured using the Child Behaviour Check List for age 11/2 to 5 years old. In addition, several socioeconomic, parental and child confounding factors are assessed.

Conclusions: This study aims to clarify the effect of mild iodine deficiency during pregnancy on the neurodevelopment of the offspring. Therefore, the results may have important implications for future public health recommendations, policies and practices in food supplementation. In addition, the results may have implications for the use of neonatal TSH screening results for monitoring the population iodine status and may lead to the definition of new TSH cut-offs for determination of the severity of iodine status and for practical use in data reporting by neonatal screening centres.
\end{abstract}

Keywords: lodine deficiency, Thyroid stimulating hormone, Child development, Cognitive development, Psychomotor development, Psychosocial development

\footnotetext{
* Correspondence: Caroline.Trumpff@wiv-isp.be

${ }^{1}$ Unit of Public Health and Surveillance, Scientific Institute of Public Health,

Brussels, Belgium

${ }^{2}$ Faculté des Sciences Psychologiques et de l'Education, Université Libre de

Bruxelles, Brussels, Belgium

Full list of author information is available at the end of the article
}

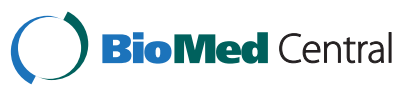

(c) 2014 Trumpff et al.; licensee BioMed Central Ltd. This is an Open Access article distributed under the terms of the Creative Commons Attribution License (http://creativecommons.org/licenses/by/2.0), which permits unrestricted use, distribution, and reproduction in any medium, provided the original work is properly credited. The Creative Commons Public Domain Dedication waiver (http://creativecommons.org/publicdomain/zero/1.0/) applies to the data made available in this article, unless otherwise stated. 


\section{Background}

According to the World Health Organization (WHO), iodine deficiency is the main cause of preventable brain damage [1]. Iodine is important for the production of thyroid hormones $(\mathrm{TH})$, which are essential for the development of the central nervous system [2]. Severe iodine deficiency may lead to perinatal mortality and mental retardation [3]. Maternal iodine deficiency during pregnancy, even at mild to moderate levels, may affect the neurodevelopment of the offspring [4]. Median urinary concentration is used to define classification of the levels of iodine intake as shown in Table 1.

Iodine deficiency is defined through three levels of severity: mild, moderate or severe. Severe iodine deficiency has been observed mainly in Central Africa and Asia and is considered to be disappeared in Europe. However, several European countries, including Belgium, still suffer from mild iodine deficiency (MID) despite implementation of salt iodization programmes as national measures to supress iodine deficiency [5-8]. From 2003 to 2007, the number of European countries which are mildly iodine deficient decreased from 23 to 14 [9] showing that iodine deficiency remains a problem in Europe. Iodine deficiency even re-emerged in countries previously iodine sufficient such as the UK [10]. With respect to Belgium, recent studies found that school aged children were iodine sufficient while women at childbearing age and pregnant women had MID $[7,8]$. It is a matter of concern as MID during pregnancy could lead to suboptimal cognitive and psychomotor outcomes in the offspring [4].

Thyroid stimulating hormone (TSH) concentration in whole blood measured at birth has been proposed as an indicator of maternal iodine status during the last trimester of pregnancy [11]. TSH controls and stimulates the production of $\mathrm{TH}$. In order to maintain circulating $\mathrm{TH}$ levels within the required range, TSH is secreted. If iodine stores are insufficient to produce TH, TSH concentration increases. Figure 1 illustrates the change in neonatal TSH concentration in case of maternal iodine sufficiency or deficiency during pregnancy.

Several studies showed that elevated TSH levels after birth were associated with suboptimal cognitive and

Table 1 Median UI in school aged children: indicator of iodine nutrition

\begin{tabular}{ll}
\hline Median UI $(\boldsymbol{\mu g} / \mathbf{l})$ & lodine nutrition \\
\hline$<20$ & Severe iodine deficiency \\
$20-49$ & Moderate iodine deficiency \\
$50-99$ & Mild iodine deficiency \\
$100-199$ & lodine sufficiency \\
$200-299$ & lodine intake more than adequate \\
$>300$ & lodine excess \\
\hline
\end{tabular}

Source: WHO, 2004 [1]. psychomotor outcomes [12-15]. Though, it is hard to claim that the observed impairments in cognitive and/or psychomotor functioning are a direct consequence of MID during gestation. An elevated TSH level at birth can be caused by several factors [16-27] and some of them affect both TSH levels and IQ in childhood [14,23,28-59]. Further studies are needed to evaluate the association between elevated TSH at birth and intellectual, psychomotor and psychosocial development of preschool children taking into account confounding factors.

In order to evaluate the efficiency of national programmes implemented to suppress iodine deficiency, adapted surveillance of the iodine status of the population is important. To monitor the iodine status of a population, median urinary iodine excretion, thyroid size, neonatal TSH concentration in blood and thyroglobulin concentration in blood can be used as indicators [60-63].

In most developed countries, neonatal screening programmes for congenital hypothyroidism are organised allowing early detection and treatment of children with thyroid hormone therapy [64]. When neonatal screening programmes are set up in a country, the WHO recommends the use of TSH results to monitor iodine status in that population [60].

The percentage of neonatal TSH screening results greater than $5 \mathrm{mU} / \mathrm{L}$ can be used to define the iodine status of a population (see Table 2) as follows: a frequency below 3\% indicates iodine sufficiency, a frequency of 3$19.9 \%$ indicates mild iodine deficiency, a frequency of 20 $39.9 \%$ indicates moderate deficiency and a frequency above $40 \%$ indicates iodine deficiency respectively $[27,60,61]$.

In several studies, the neonatal TSH results have been used to assess the iodine status of the population [65-68]. However the cut-off of $5 \mathrm{mU} / \mathrm{L}$ recommended by the WHO has been criticized [69-71]. In addition, a percentage below $3 \%$ of the TSH results greater than $5 \mathrm{mU} / \mathrm{L}$ was found in populations with MID [27,72] failing to detect MID in those population. Since the proposed cut-off of percentage of TSH screening results $>5 \mathrm{mU} / \mathrm{L}$ below $3 \%$ is not sensitive enough to detect MID, it should be reassessed.

\section{Research objectives}

The purpose of the PSYCHOTSH study is to assess the relationship between neonatal TSH levels and intellectual, psychomotor and psychosocial development of children aged 4-5 years old. It is hypothesized that children with a neonatal TSH level (at day 3 to 5) in the highest quintile, used as marker of lower intrauterine iodine supply, have a higher risk to develop psychomotor, cognitive as well as behavioural problems. In addition, the study aims to reassess the cut-off of $5 \mathrm{mU} / \mathrm{L}$ of neonatal TSH concentration in whole blood proposed by the WHO [60] to 


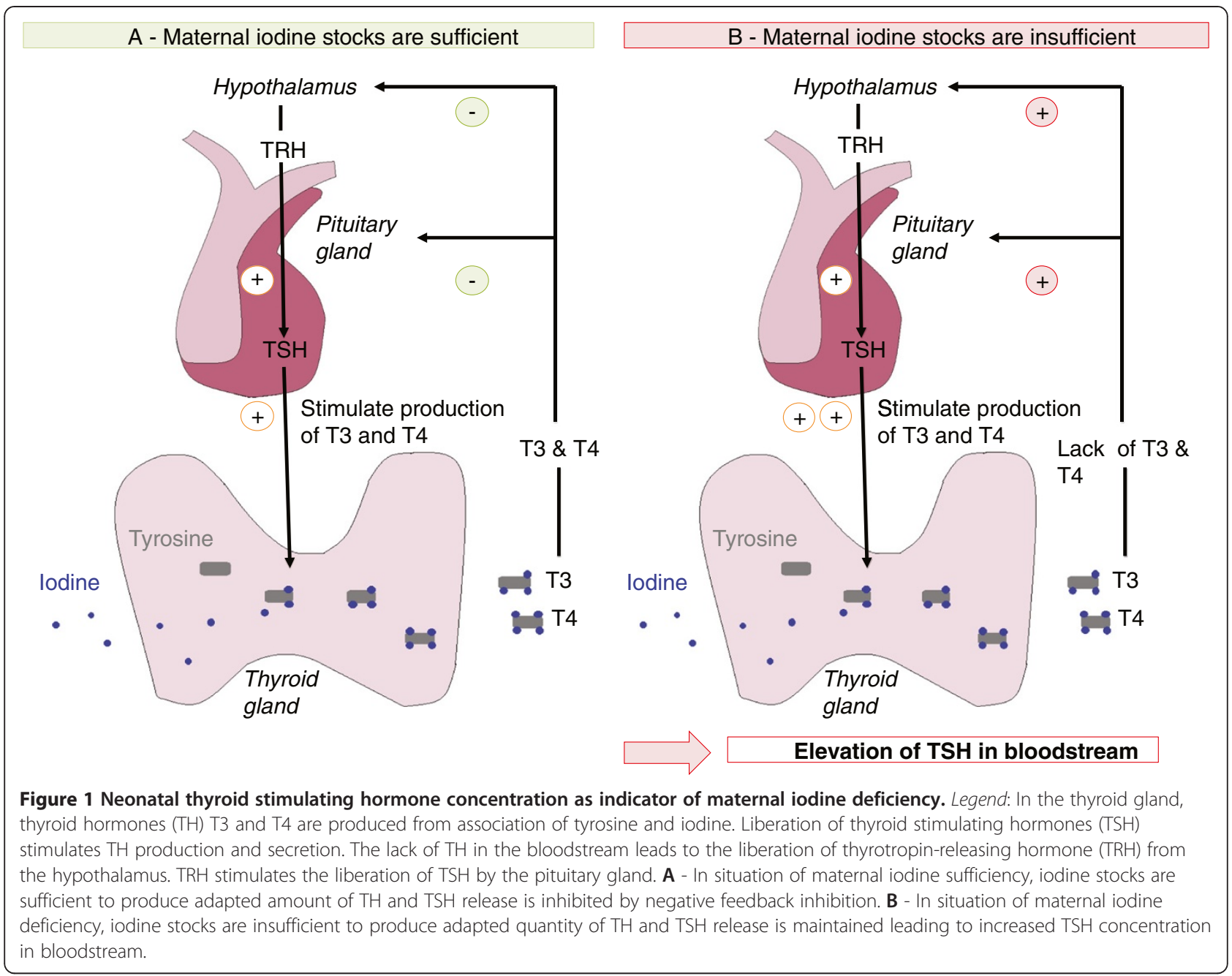

monitor iodine status in a population. The relationship found between TSH level and children's intellectual, psychomotor and psychosocial development will be used to define a cut-off to indicate iodine deficiency using ROC curve analysis.

\section{Methods}

\section{TSH determination}

The children were selected from the total sample of neonates screened in 2008 and 2009 by the Brussels newborn screening centre for metabolic disorders (Laboratoire de

Table 2 Percentage of neonatal TSH screening results $>5 \mathrm{mU} / \mathrm{L}$ at screening: indicator of iodine nutrition

\begin{tabular}{ll}
\hline Percentage of neonatal $\mathbf{T S H}>\mathbf{5} \mathbf{~} \mathbf{U} / \mathbf{L}$ & lodine nutrition \\
\hline $0-3 \%$ & lodine sufficiency \\
$3-19.9 \%$ & Mild iodine deficiency \\
20 à 39,9\% & Moderate iodine deficiency \\
$\geq 40 \%$ & Severe iodine deficiency \\
\hline
\end{tabular}

Source: WHO, 1994 [60].
Pédiatrie, Université Libre de Bruxelles, Brussels). Neonatal TSH level was measured in dried blood spots on filter paper collected by heel stick 3 to 5 days after birth. The measurement of TSH was performed using a time-resolved fluroimmunoassay (Autodelfia method) on filter paper [73].

\section{Subjects}

A sample size of 315 children was determined based on a detection probability (or power) of $95 \%$, a significance level alpha of $5 \%$ and a correlation factor between TSH and IQ of 0.2. An anticipated drop-out of $20 \%$ was taken into account. 380 children aged 4-5 years old with a neonatal TSH concentration in the range $0-15 \mathrm{mU} / \mathrm{L}$ were included in the study. Children were stratified by sex and by TSH level using a stratified sampling methodology. The details of the sample are shown in Table 3.

For each sex and TSH-interval $(0-1,1-2,2-3,3-4$, $4-5,5-6,6-7,7-8,8-9$ and 9-15 mU/L) 19 newborns were selected randomly. In addition, the day of collection was taken into account. Exclusion criteria were: 1) neonatal TSH level of $15 \mathrm{mU} / \mathrm{L}$ or higher as this is the 
Table 3 Sample stratification of newborns by neonatal TSH level and by sex

\begin{tabular}{llll}
\hline Neonatal TSH level $\mathbf{~} \mathbf{U} / \mathbf{L}$ & Boys & Girls & Total \\
\hline $1-0$ & 19 & 19 & 38 \\
$1-2$ & 19 & 19 & 38 \\
$2-3$ & 19 & 19 & 38 \\
$3-4$ & 19 & 19 & 38 \\
$4-5$ & 19 & 19 & 38 \\
$5-6$ & 19 & 19 & 38 \\
$6-7$ & 19 & 19 & 38 \\
$7-8$ & 19 & 19 & 38 \\
$8-9$ & 19 & 19 & 38 \\
$9-15$ & 19 & 19 & 38 \\
Total & 190 & 190 & 380 \\
\hline
\end{tabular}

cut-off of TSH level for suspected congenital hypothyroidism, 2) prematurity ( $<37$ weeks) and low birth weight $(<2500 \mathrm{~g})$ as this may induce TSH elevation at birth and alteration of neurodevelopment, 3) neurological disease of the children and 4) non-French speaking children (in order to perform psychological testing in the children's mother tongue). For each selected infant, 3 replacements (with same TSH level and sex) were randomly selected, in case of refusals or noncontactable individuals.

\section{Approval by Ethical Committee for human subjects and by Privacy Commission}

A written informed consent is obtained from the parents before the start of the procedure (i.e. home visit). The study design, the data collection procedures, the consent form and the invitation letter were approved by the Ethical Committee of the Erasme hospital (Universite Libre de Bruxelles, Brussels) in accordance with the Code of Ethics of the World Medical Association for experiments involving humans (Declaration of Helsinki). The study was also approved by the Belgian Privacy Commission.

\section{Psychological testing}

Psychometric assessment is done by 7 trained clinical psychologists during a home visit. Psychologists are blinded for the neonatal TSH levels of the selected children. Before test administration, the parents are asked to provide a quiet room and leave the psychologist alone with the child. If the child does not feel comfortable being left alone with the psychologist, one adult may stay in the room with the child, outside his or her field of view and without interrupting the psychologist.

Cognitive development is assessed using age-appropriate cognitive tests, the French version of the Wechsler Preschool and Primary Scale of Intelligence - third edition (WPPSI-III) [74,75]. The WPPSI-III is a test administered individually and allows to measure intelligence of children aged 2 years 6 months to 7 years 3 months; it is divided into 2 age groups: 2 years 6 months to 3 years 11 months old and 4 years to 7 years 3 months old. The test contains 14 subtests: 7 verbal tests, 5 performance tests and 2 processing speed tests. These subtests allow calculating a full scale Intelligence Quotient (IQ), a verbal IQ, a performance $\mathrm{IQ}$, a processing speed quotient and an optional score of general language knowledge.

Psychomotor development is assessed using the French adapted version of the Charlop-Atwell Scale of Motor Coordination [76,77]. This individually administered test evaluates gross motor coordination abilities of children of $3^{1 / 2}$ to 6 years old using 6 subtests. The scale contains a subjective rating (based on quality of performance) in addition to an objective subtest rating (based on accuracy of performance).

Psychosocial development is evaluated using the French version of the Child Behaviour Check List (CBCL) for ages $1 \frac{1}{2}$ to 5 years old [78]. This test allows obtaining 3 scores: a total problem score, a score on internalizing problems and a score on externalizing problems. Internalizing problems represent problems of the self, like withdrawal, anxiety or depression. Externalizing problems are problems with others, problems of conflicts or problems with authority, like aggressive behaviour or attention problems. The total problem score includes these 2 scores plus a score on sleeping problems and a score on "other problems". In order to calculate the scores, the Windows Software Assessment Data Manager is used [78].

\section{Children anthropometric measurements}

Next to psychometric assessment, the actual weight, height and head circumference of the child are measured using SECA 815 or SECA 804 weight scales, SECA 214 stadiometers and SECA 212 flexible measuring tapes.

\section{Children urinary iodine concentration}

A sample of urine is collected from the child during the home visit. The aim is to determine the current iodine status among the children included in the study. All urine samples are frozen and kept at $-80^{\circ} \mathrm{C}$ until analysis. Analyses of the samples are performed at the Erasme Hospital. Urinary iodine excretion is measured using a modification of the Sandelle-Kolthoff reaction with spectrophotometric detection [79].

\section{Data collection of covariates, effect modifiers and descriptive variables}

The variables collected in this study as covariates, effect modifiers and descriptive variables are shown in Table 4 .

Information about covariates and effect modifiers is gathered from the data provided by the ULB newborn screening centre for metabolic disorders. Additional 
Table 4 Covariates, effects modifiers and descriptive variables of the PSYCHOTSH study

\begin{tabular}{|c|c|c|c|}
\hline Covariates & Effect modifiers & & Descriptive variables \\
\hline Association of elevation of TSH and impaired & Elevation of TSH & Neurodevelopment and/or & \\
\hline Neurodevelopment & & psychometric testing & \\
\hline Foetus in utero exposure to: & Foetus in utero exposure to: & Child related factor: & $\begin{array}{l}\text { Zip code of the house of the } \\
\text { child }\end{array}$ \\
\hline & & Child bilinguism & \\
\hline lodine excess & lodine containing drugs & Chronic disease of the child & Date of birth of the \\
\hline TSH-receptor blocking antibodies from mothers & & Attending nursery school & child, mother and father \\
\hline & & & $\begin{array}{l}\text { Height and weight of the child } \\
\text { at birth }\end{array}$ \\
\hline Antithyroid drugs & $\begin{array}{l}\text { Exposition of the new-born } \\
\text { during neonatal period: }\end{array}$ & $\begin{array}{l}\text { Previous intellectual } \\
\text { assessment }\end{array}$ & $\begin{array}{l}\text { Actual height, weight of child, } \\
\text { mother and father }\end{array}$ \\
\hline & & Child negative life events & \\
\hline Contrast agents & Exposition to cold & Parenting stress & \\
\hline Organochlorides & Surgical hypothermia & Dysfunctional parenting & $\begin{array}{l}\text { Head circumference of the } \\
\text { child }\end{array}$ \\
\hline Lithium & Delivery by forceps extraction & & \\
\hline Cadmium & & & Household composition \\
\hline Maternal smoking & TSH testing: & & $\begin{array}{l}\text { Nationality and origin of the } \\
\text { child and the parents }\end{array}$ \\
\hline Maternal alcohol consumption & Timing of blood sampling & & \\
\hline & TSH assay used & Parents related factors: & $\begin{array}{l}\text { Maternal/paternal education } \\
\text { and employment }\end{array}$ \\
\hline & & Level of education & Household incomes \\
\hline & & Household incomes & Marital status and custody \\
\hline & & Maternal age at birth & \\
\hline & & Parity & \\
\hline $\begin{array}{l}\text { Exposition of the new-born during neonatal } \\
\text { period: }\end{array}$ & & & \\
\hline Exposure to iodine-containing antiseptics & & Gravidity & \\
\hline Perinatal anoxia & & $\begin{array}{l}\text { Pre-pregnancy body mass } \\
\text { index }\end{array}$ & \\
\hline & & $\begin{array}{l}\text { Weight gain of the mother } \\
\text { during pregnancy }\end{array}$ & \\
\hline & & $\begin{array}{l}\text { Maternal diabetes during } \\
\text { pregnancy }\end{array}$ & \\
\hline & & $\begin{array}{l}\text { Maternal diabetes treatment } \\
\text { during pregnancy }\end{array}$ & \\
\hline & & $\begin{array}{l}\text { Maternal mental health } \\
\text { disorders }\end{array}$ & \\
\hline & & Maternal poor social support & \\
\hline & & Marital discord & \\
\hline
\end{tabular}

information about pregnancy and about the period between birth and the home visit at 4-5 year old is collected using a self-report questionnaire filled in by the mother and from consultation of the health booklet of the child by the psychologist. In addition, the name of the gynaecologist is requested in the informed consent form in case additional information will be needed regarding the health of the mother during pregnancy.
Concerning pregnancy the following data are collected: exposure to iodine excess (use of iodine- containing antiseptics), intake of iodine-containing drugs, exposure to organochlorides, exposure to cadmium, lithium intake, thyroid disease of the mother, antithyroid drug intake, diabetes and treatment of diabetes, alcohol consumption and cigarette smoking, maternal age at birth, reproductive history, parity, gravidity, pre- 
pregnancy body mass index (BMI), weight gain of the mother during pregnancy.

Concerning the neonatal period the following data are collected: exposure to iodine excess (use of iodinecontaining antiseptics), health problems of the newborn, type of delivery, season of birth and perinatal anoxia.

Concerning the period between birth and the home visit the following information is gathered about the parents: maternal/paternal education and employment, household income, marital status, area of residence, maternal age and information about housing.

Concerning the period between birth and the home visit the following information is gathered about the child: breastfeeding, chronic disease, attending nursery school, bilingualism, previous intellectual assessment.

In addition a self-report questionnaire is used to assess several psychological factors supposed to influence mental development: child's negative life events, maternal mental health, maternal social support, marital discord and parent-child interactions. Some of the questions were adapted from existing questionnaires [80-83].

\section{Discussion and conclusion}

Several studies showed that elevated TSH levels after birth were associated with suboptimal cognitive and psychomotor outcomes [12-15]. However, many factors may influence neonatal TSH [16-27] concentration and some of them may affect both TSH levels and neurodevelopment in childhood [14,23,28-59]. The present study aims to evaluate association between elevated TSH at birth and intellectual, psychomotor and psychosocial development of preschool children taking into account confounding factors. This study aims to clarify the effect of MID during pregnancy on the neurodevelopment of the offspring. Therefore, the results may have important implications for future public health recommendations, policies and practices in food supplementation.

In order to evaluate the efficiency of national programmes implemented to suppress iodine deficiency, adapted surveillance of the iodine status of the population is needed. To monitor the iodine status of a population, neonatal TSH whole blood concentration can be used as an indicator [60]. The proposed cut-off percentage below $3 \%$ of the TSH results $>5 \mathrm{mU} / \mathrm{L}$ was shown to be not sensitive enough to detect MID [27,72]. The present study aims to reassess the recommended cut-off of $>5 \mathrm{mU} / \mathrm{L}$ using ROC curve analysis. Therefore, the results of the study could help to clarify the potential use of neonatal TSH screening results for monitoring the iodine status of populations. Furthermore, the results could lead to the definition of a new neonatal TSH cut-off for monitoring the iodine status of populations. The results could also have an impact on the definition of the cut-off of TSH levels used for reporting by neonatal screening centres.

\section{Abbreviations}

MID: Mild iodine deficiency; ROC: Receiver operating characteristic; TH: Thyroid hormone; TRH: Thyrotropin-releasing hormone; TSH: Thyroid-stimulating hormone; WHO: World Health Organization.

\section{Competing interest}

All authors declare not having any conflict of interest with regard to this study.

\section{Acknowledgements}

The authors acknowledge the financial support from "Belgian Federal Science Policy Office" (BELSPO) and from the "Fonds de la Recherche Scientifique Medicale" (F.R.S.M.) for operating costs. All authors contributed to build up the protocol of the study and critically revised the draft versions of the manuscript.

\section{Author details}

'Unit of Public Health and Surveillance, Scientific Institute of Public Health, Brussels, Belgium. ${ }^{2}$ Faculté des Sciences Psychologiques et de l'Education, Université Libre de Bruxelles, Brussels, Belgium. ${ }^{3}$ Faculty of Psychology and Educational Sciences, Vrije Universiteit Brussel, Brussels, Belgium.

${ }^{4}$ Department of Paediatric Endocrinology, UZ Brussel, Brussels, Belgium.

Received: 20 November 2013 Accepted: 18 April 2014

Published: 18 August 2014

\section{References}

1. WHO: Iodine status worldwide. Geneva, Switzerland: World Health Organization; 2004.

2. Corvilain B, Contempre B, Longombe AO, Goyens P, Gervy-Decoster C, Lamy $F$, Vanderpas JB, Dumont JE: Selenium and the thyroid: how the relationship was established. Am J Clin Nutr 1993, 57:244S-248S.

3. Zimmermann MB, Jooste PL, Pandav CS: lodine-deficiency disorders. Lancet 2008, 372:1251-1262.

4. Trumpff C, De Schepper J, Tafforeau J, Van Oyen H, Vanderfaeillie J, Vandevijvere S: Mild iodine deficiency in pregnancy in Europe and its consequences for cognitive and psychomotor development of children: a review. J Trace Elem Med Biol 2013, 27:174-183.

5. WHO: Iodine deficiency in Europe: a continuing public health problem. Geneva, Switzerland: World Health Organization; 2007.

6. De Benoist B, McLean E, Andersson M, Rogers L: lodine deficiency in 2007: global progress since 2003. Food Nutr Bull 2008, 29:195-202.

7. Vandevijvere S, Mourri AB, Amsalkhir S, Avni F, Van Oyen H, Moreno-Reyes R: Fortification of bread with iodised salt corrected iodine deficiency in school-aged children but not in their mothers: A National Cross- sectional survey in Belgium. Thyroid 2012, 22:1046-1053.

8. Vandevijvere S, Amsalkhir S, Mourri BA, Van Oyen H, Moreno Reyes R: lodine deficiency among Belgian pregnant women not fully corrected by iodine-containing multivitamins: a national cross-sectional study. $\mathrm{Br} \mathrm{J}$ Nutr 2013, 109(12):2276-2284.

9. Zimmermann MB, Andersson M: Prevalence of iodine deficiency in Europe in 2010. Ann Endocrinol (Paris) 2011, 72:164-166.

10. Vanderpump MP, Lazarus JH, Smyth PP, Laurberg P, Holder RL, Boelaert K, Franklyn JA: lodine status of UK schoolgirls: a cross-sectional survey. Lancet 2011, 377:2007-2012.

11. Zimmermann MB, Aeberli I, Torresani T, Burgi H: Increasing the iodine concentration in the Swiss iodized salt program markedly improved iodine status in pregnant women and children: a 5 -y prospective national study. Am J Clin Nutr 2005, 82:388-392.

12. Calaciura F, Mendorla G, Distefano M, Castorina S, Fazio T, Motta RM, Sava L, Delange F, Vigneri R: Childhood IQ measurements in infants with transient congenital hypothyroidism. Clin Endocrinol (Oxf) 1995, 43:473-477.

13. Riano Galan I, Sanchez MP, Pilar Mosteiro DM, Rivas Crespo MF: Psychointellectual development of 3 year-old children with early gestational iodine deficiency. J Pediatr Endocrinol Metab 2005, 18(Suppl 1):1265-1272.

14. Freire C, Ramos R, Amaya E, Fernandez MF, Santiago-Fernandez P, LopezEspinosa MJ, Arrebola JP, Olea N: Newborn TSH concentration and its association with cognitive development in healthy boys. Eur J Endocrinol 2010, 163:901-909. 
15. Belcari F, Placidi G, Guzzetta A, Tonacchera M, Ciampi M, Bartoli A, Scaramuzzo RT, Frumento P, Cioni G, Pinchera A, Boldrini A, Ghirri P: Thyroid-stimulating hormone levels in the first days of life and perinatal factors associated with sub-optimal neuromotor outcome in pre-term infants. J Endocrinol Invest 2011, 34:e308-e313.

16. Becks GP, Burrow GN: Thyroid disease and pregnancy. Med Clin North Am 1991, 75:121-150.

17. Karlsson FA, Dahlberg PA, Alm J, Larsson A, Felding I: Maternal TSHreceptor antibodies and TSH antibodies in screening for congenital hypothyroidism. Acta Paediatr Scand 1986, 75:756-761.

18. Mengreli C, Maniati-Christidi M, Kanaka-Gantenbein C, Girginoudis P, Vagenakis AG, Dacou-Voutetakis C: Transient congenital hypothyroidism due to maternal autoimmune thyroid disease. Hormones (Athens) 2003 2:113-119.

19. Smallridge RC, Ladenson PW: Hypothyroidism in pregnancy: consequences to neonatal health. J Clin Endocrinol Metab 2001, 86:2349-2353.

20. Cheron RG, Kaplan MM, Larsen PR, Selenkow HA, Crigler JF Jr: Neonatal thyroid function after propylthiouracil therapy for maternal Graves' disease. N Engl J Med 1981, 304:525-528.

21. Ruppert F, Sulyok E, Varga F, Csaba IF, Petz A: Thyrotropin and prolactin response to ambient temperature in newborn infants. Acta Paediatr Acad Sci Hung 1982, 23:189-194.

22. Wilber JF, Baum D: Elevation of plasma TSH during surgical hypothermia. J Clin Endocrinol Metab 1970, 31:372-375.

23. Rashmi, Seth A, Sekhri T, Agarwal A: Effect of perinatal factors on cord blood thyroid stimulating hormone levels. J Pediatr Endocrinol Metab 2007, 20:59-64.

24. Fisher DA, Klein AH: Thyroid development and disorders of thyroid function in the newborn. N Engl J Med 1981, 304:702-712.

25. Abuid J, Stinson DA, Larsen PR: Serum triiodothyronine and thyroxine in the neonate and the acute increases in these hormones following delivery. J Clin Invest 1973, 52:1195-1199.

26. Rose SR, Nisula BC: Circadian variation of thyrotropin in childhood. J Clin Endocrinol Metab 1989, 68:1086-1090.

27. Vandevijvere S, Coucke W, Vanderpas J, Trumpff C, Fauvart M, Meulemans A, Marie S, Vincent MF, Schoos R, Boemer F, Vanwynsberghe T, Philips E, Eyskens F, Wuyts B, Selimaj V, Kirkpatrick C, Van Overmeire B, Van Oyen H, Moreno-Reyes R: Neonatal thyroid-stimulating hormone concentrations in Belgium: a useful indicator for detecting mild iodine deficiency? PLoS One 2012, 7:e47770.

28. Gao B, Yin G: Effects of high-dose iodine on brain development in mice. Zhonghua Yu Fang Yi Xue Za Zhi 1997, 31:134-136.

29. Zao J: lodine deficiency and iodine excess in Jiangsu Province. China: Wageningen University; 2001

30. Nishiyama S, Mikeda T, Okada T, Nakamura K, Kotani T, Hishinuma A: Transient hypothyroidism or persistent hyperthyrotropinemia in neonates born to mothers with excessive iodine intake. Thyroid 2004, 14:1077-1083.

31. Thomas JV, Collett-Solberg PF: Perinatal goiter with increased iodine uptake and hypothyroidism due to excess maternal iodine ingestion. Horm Res 2009, 72:344-347.

32. Pavan-Senn CC, Nesi-Franca S, Pelaez J, Pereira RM, Boguszewski MC, Sandrini NR, Lacerda FL: Transient neonatal hypothyroidism due to amiodarone administration during pregnancy-two cases report and review of literature. Arq Bras Endocrinol Metabol 2008, 52:126-130.

33. Bartalena L, Bogazzi F, Braverman LE, Martino E: Effects of amiodarone administration during pregnancy on neonatal thyroid function and subsequent neurodevelopment. J Endocrinol Invest 2001, 24:116-130.

34. Magee LA, Downar E, Sermer M, Boulton BC, Allen LC, Koren G: Pregnancy outcome after gestational exposure to amiodarone in Canada. Am J Obstet Gynecol 1995, 172:1307-1311.

35. De Wolf D, De Schepper J, Verhaaren H, Deneyer M, Smitz J, Sacre-Smits L: Congenital hypothyroid goiter and amiodarone. Acta Paediatr Scand 1988, 77:616-618.

36. Vanhaesebrouck P, Verstraete AG, De PC, Smets K, Zecic A, Craen M: Transplacental passage of a nonionic contrast agent. Eur J Pediatr 2005 , 164:408-410.

37. Ribas-Fito N, Sala M, Cardo E, Mazon C, De Muga ME, Verdu A, Marco E, Grimalt JO, Sunyer J: Organochlorine compounds and concentrations of thyroid stimulating hormone in newborns. Occup Environ Med 2003, 60:301-303.
38. Lopez-Espinosa MJ, Vizcaino E, Murcia M, Fuentes V, Garcia AM, Rebagliato M, Grimalt JO, Ballester F: Prenatal exposure to organochlorine compounds and neonatal thyroid stimulating hormone levels. J Expo Sci Environ Epidemiol 2010, 20:579-588.

39. Grandjean P, Landrigan PJ: Developmental neurotoxicity of industrial chemicals. Lancet 2006, 368:2167-2178.

40. Frassetto F, Tourneur MF, Barjhoux CE, Villier C, Bot BL, Vincent F: Goiter in a newborn exposed to lithium in utero. Ann Pharmacother 2002, 36:1745-1748.

41. Shirkey HC: Human experiences related to adverse drug reactions to the fetus or neonate from some maternally administered drugs. Adv Exp Med Biol 1972, 27:17-30.

42. Khashu M, Chessex P, Chanoine JP: lodine overload and severe hypothyroidism in a premature neonate. J Pediatr Surg 2005, 40:E1-E4.

43. Chanoine JP, Boulvain M, Bourdoux P, Pardou A, Van Thi HV, Ermans AM, Delange F: Increased recall rate at screening for congenital hypothyroidism in breast fed infants born to iodine overloaded mothers. Arch Dis Child 1988, 63:1207-1210.

44. Weber G, Vigone MC, Rapa A, Bona G, Chiumello G: Neonatal transient hypothyroidism: aetiological study: Italian Collaborative Study on Transient Hypothyroidism. Arch Dis Child Fetal Neonatal Ed 1998, 79:F70-F72.

45. Gottfried AW: Intellectual consequences of perinatal anoxia. Psychol Bull 1973, 80:231-242.

46. Schachter FF, Apgar V: Perinatal asphyxia and psychologic signs of brain damage in childhood. Pediatrics 1959, 24:1016-1025.

47. Olivieri A, Medda E, De AS, Valensise H, De FM, Fazzini C, Cascino I, Cordeddu V, Sorcini M, Stazi MA: High risk of congenital hypothyroidism in multiple pregnancies. J Clin Endocrinol Metab 2007, 92:3141-3147.

48. Deary IJ, Pattie A, Wilson V, Whalley LJ: The cognitive cost of being a twin: two whole-population surveys. Twin Res Hum Genet 2005, 8:376-383.

49. Natalucci G, Seitz J, von SK, Bucher HU, Molinari L, Jenni OG, Latal B: The role of birthweight discordance in the intellectual and motor outcome for triplets at early school age. Dev Med Child Neurol 2011, 53:822-828.

50. Ng SM, Wong SC, Paize F, Chakkarapani E, Newland P, Isherwood D, Didi M: Multivariate analyses of factors that affect neonatal screening thyroid stimulating hormone. J Pediatr Endocrinol Metab 2011, 24:727-732.

51. Petrini JR, Dias T, McCormick MC, Massolo ML, Green NS, Escobar GJ: Increased risk of adverse neurological development for late preterm infants. J Pediatr 2009, 154:169-176.

52. Lundgren EM, Tuvemo T, Gustafsson J: Short adult stature and overweight are associated with poor intellectual performance in subjects born preterm. Horm Res Paediatr 2011, 75:138-145.

53. Caravale B, Tozzi C, Albino G, Vicari S: Cognitive development in low risk preterm infants at 3-4 years of life. Arch Dis Child Fetal Neonatal Ed 2005, 90:F474-F479.

54. Pietz J, Peter J, Graf R, Rauterberg-Ruland I, Rupp A, Sontheimer D, Linderkamp O: Physical growth and neurodevelopmental outcome of nonhandicapped low-risk children born preterm. Early Hum Dev 2004, 79:131-143.

55. Goldenberg RL, Dubard MB, Cliver SP, Nelson KG, Blankson K, Ramey SL, Herman A: Pregnancy outcome and intelligence at age five years. Am J Obstet Gynecol 1996, 175:1511-1515.

56. Goyen TA, Lui K, Hummell J: Sensorimotor skills associated with motor dysfunction in children born extremely preterm. Early Hum Dev 2011, 87:489-493.

57. Clapin H, Lewis BD, Greed L, Dawkins H, O'Leary P: Factors influencing neonatal thyroid-stimulating hormone concentrations as a measure of population iodine status. J Pediatr Endocrinol Metab 2014, 27:101-106.

58. Lawlor DA, Najman JM, Batty GD, O'Callaghan MJ, Williams GM, Bor W: Early life predictors of childhood intelligence: findings from the MaterUniversity study of pregnancy and its outcomes. Paediatr Perinat Epidemiol 2006, 20:148-162.

59. Rieger-Fackeldey E, Blank C, Dinger J, Steinmacher J, Bode H, Schulze A: Growth, neurological and cognitive development in infants with a birthweight $<501 \mathrm{~g}$ at age 5 years. Acta Paediatr 2010, 99:1350-1355.

60. WHO, UNICEF, ICCIDD: Indicators for assessing iodine deficiency disorders and their control through salt iodisation. Geneva: WHO; 1994. WHO/NUT/94.6.

61. Delange F: Neonatal thyroid screening as a monitoring tool for the control of iodine deficiency. Acta Paediatr Supp/ 1999, 88:21-24.

62. Delange F: Neonatal screening for congenital hypothyroidism: results and perspectives. Horm Res 1997, 48:51-61. 
63. Delange F: Screening for congenital hypothyroidism used as an indicator of the degree of iodine deficiency and of its control. Thyroid 1998, 8:1185-1192.

64. WHO, UNICEF, ICCIDD: Assessment of iodine deficiency disorders and monitoring their elimination: a guide for programme managers. Geneva: World Health Organisation; 2001.

65. Costante G, Grasso L, Ludovico O, Marasco MF, Nocera M, Schifino E, Rivalta L, Capula C, Chiarella R, Filetti S, Parlato G: The statistical analysis of neonatal TSH results from congenital hypothyroidism screening programs provides a useful tool for the characterization of moderate iodine deficiency regions. J Endocrinol Invest 1997, 20:251-256.

66. Mikelsaar RV, Viikmaa M: Neonatal thyroid-stimulating hormone screening as an indirect method for the assessment of iodine deficiency in Estonia. Horm Res 1999, 52:284-286.

67. Copeland DL, Sullivan KM, Houston R, May W, Mendoza I, Salamatullah Q, Solomons N, Nordenberg D, Maberly GF: Comparison of neonatal thyroidstimulating hormone levels and indicators of iodine deficiency in school children. Public Health Nutr 2002, 5:81-87.

68. Gyurjyan RH, Lugovska R, Vevere P, van der Haar F: Newborn thyrotropin screening confirms iodine deficiency in Latvia. Eur J Clin Nutr 2006, 60:688-690.

69. Burns R, Mayne PD, O'Herlihy C, Smith DF, Higgins M, Staines A, Smyth PP: Can neonatal TSH screening reflect trends in population iodine intake? Thyroid 2008, 18:883-888.

70. Rajatanavin R: lodine deficiency in pregnant women and neonates in Thailand. Public Health Nutr 2007, 10:1602-1605.

71. Gruneiro-Papendieck L, Chiesa A, Mendez V, Bengolea S, Prieto L: Neonatal TSH levels as an index of iodine sufficiency: differences related to time of screening sampling and methodology. Horm Res 2004, 62:272-276.

72. Travers CA, Guttikonda K, Norton CA, Lewis PR, Mollart LJ, Wiley V, Wilcken B, Eastman CJ, Boyages SC: lodine status in pregnant women and their newborns: are our babies at risk of iodine deficiency? Med J Aust 2006, 184:617-620.

73. Soini $\mathrm{E}, \mathrm{Kojola} \mathrm{H}$ : Time-resolved fluorometer for lanthanide chelates-a new generation of nonisotopic immunoassays. Clin Chem 1983, 29:65-68.

74. Wechsler D: WechslerPreschool and Primary Scale of Intelligence - Revised. San Antonio, TX: The Psychological Corporation; 1989.

75. Wechsler D: Manual for the Wechsler Preschool and Primary Scale of Intelligence. San Antonio, TX: The Psychological Corporation; 1967.

76. Charlop M, Atwell CW: The Charlop-Atwell scale of motor coordination: a quick and easy assessment of young children. Percept Mot Skills 1980, 50:1291-1308.

77. Albaret JM, Noack N: Manuel de l'échelle de coordinations lotrices de CharlopAtwell. Paris: Editions du Centre de Psychologie appliquée; 1994.

78. Achenbach TM, Rescorla LA: Manual for the ASEBA Preschool Forms \& Profiles. Burlington, VT: University of Vermont, Research Center for Children, Youth \& Families; 2000

79. Pino S, Fang SL, Braverman LE: Ammonium persulfate: a safe alternative oxidizing reagent for measuring urinary iodine. Clin Chem 1996, 42:239-243.

80. Coddington RD: The significance of life events as etiologic factors in the diseases of children - II: A study of a normal population. J Psychosom Res 1972, 16:205-213.

81. Goldberg D, Williams P: A user's guide to the General Health Questionnaire. Berkshire: NFER-NELSON; 1988.

82. Goldberg DP: Manual of the General Health Questionnaire. Traduction française de W. Bettschart \& M. Bolognini. In L'évaluation clinique standardisée en psychiatrie. Edited by Pariente P, Guelfi JD, Smith M, Guelfi JD. Paris: Editions Médicales Pierre Fabre; 1978.

83. Baillargeron J, Dubois $G$, Marineau R: Traduction française de l'échelle d'ajustement dyadique. Revue canadienne des sciences du comportement 1986, 18:25-34

doi:10.1186/2049-3258-72-27

Cite this article as: Trumpff et al.: Protocol of the PSYCHOTSH study: association between neonatal thyroid stimulating hormone concentration and intellectual, psychomotor and psychosocial development at 4-5 year of age: a retrospective cohort study. Archives of Public Health 2014 72:27.

\section{Submit your next manuscript to BioMed Central and take full advantage of:}

- Convenient online submission

- Thorough peer review

- No space constraints or color figure charges

- Immediate publication on acceptance

- Inclusion in PubMed, CAS, Scopus and Google Scholar

- Research which is freely available for redistribution
C Biomed Central 